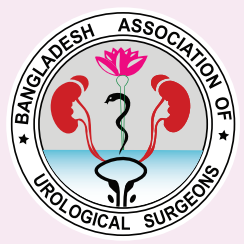

\title{
Prospect of Cadaveric Transplantation in Bangladesh
}

There are two cores of renal disease patients in Bangladesh. Every year 40 thousands people are affected with renal diseases. Only 5\%-10\% of the affected people can be provided with treatment. Because the treatment cost of renal failure is very high. Every year thirty five thousand patients die due to renal failure. Among the renal failure patients $75 \%$ patients can not understand that they are suffering from the dreaded killer disease ${ }^{1}$.

Kidney transplantation is the most successful treatment of renal failure for over five decades. The improvement in organ transplantation over the decades is due to improved technology, understanding of rejection and discovery of renal immune suppressant drugs. Every year death tolls to near about 35 thousands due to renal failure ${ }^{4}$. Only small percentage of the patients becomes lucky enough to undergo successful living related renal transplantation. Scarcity of the donor is one of the main barriers in this situation. Deceased donor is the main source of organ in the developed world whereas in developing countries, we are lack behind to start deceased organ transplant

In 1965 first cadaver kidney transplant was carried in spain. Over the time they became capable to establish organization transplant model. Upto 1997, 92\% KT performed from cadaver organ donation ${ }^{3}$.

There is lack of orientation among the public regarding donation of organ in the community, both in living and deceased organ transplant. There is also lack of interest among the physicians and surgeons regarding the organ transplantation. ICU specialist are not keen to declare brain death and the brain death committee are therefore not willing to declare brain death. There is no training program for transplant coordinator and grief councilor, both of whom are needed after brain death declaration.

In order to encourage solid organ transplantation, The government of Bangladesh has recently passed revised new version of Organ Act Law in January, 2018.
This Act expanded the horizons of living donor pool and stress the need for deceased organ transplantation. Infra structure of intensive care unit, brain death Committee, authentication committee, medical board, transplant coordinator and National committee for deceased organ transplantation, all being well defined ${ }^{2}$.

The success of organ transplantation program is depend on our will power. At present we have transplant surgeon, ICU unit, ICU specialists, brain death committee, transplant coordinator and organ failure recipients, laboratory facility and operation theatre. If we determine, we can soon start the $1^{\text {st }}$ deceased kidney transplantation.

Let us work together and start deceased transplant for the benefit of organ failure patients who are dying every day.

\author{
Dr. Md. Habibur Rahman (Dulal) \\ Professor \\ Renal Transplantation Division \\ Department of Urology \\ Bangabandhu Sheikh Mujib Medical University \\ Shahbag, Dhaka-1000, Bangladesh \\ E-mail: dulaluro@yahoo.com
}

\section{References:}

1. Kuhrs. Chronic renal failure management. Lancet 1991; 338-423.

2. HU Rashid. Progress of renal transplantation in Bangladesh. Booklet of society of organ transplantation, Bangladesh 2018:4.

3. L Garcia Aparicio, JM Grinyo, MA Viedma, MT Aguayo, J Lioveras and C Constante. 1999, 31, 346-350.

4. M Ali. Organ transplantation in Bangladesh challenges and opportunities; Ibrahim Med. Coll. J. 2012, 6(1): i-ii. 